\title{
Changes in diet quality and home food environment in preschool children following weight management
}

Shannon M. Robson ${ }^{1 *}$ D , Melissa L. Ziegler ${ }^{2}$, Mary Beth McCullough ${ }^{3}$, Cathleen Odar Stough $^{4}$, Cynthia Zion $^{5}$, Stacey L. Simon ${ }^{6}$, Richard F. Ittenbach, ${ }^{7,8}$ and Lori J. Stark ${ }^{5,7}$

\begin{abstract}
Background: Family-based obesity treatment interventions can successfully reduce energy intake in preschoolers. An implicit goal of obesity treatment interventions is to improve diet quality, but diet quality has been less examined as a treatment outcome in studies of preschoolers. The purpose of this study was to conduct a secondary analysis comparing the change in diet quality and home food environment in preschoolers assigned to a behavioral family-based obesity intervention (LAUNCH), motivational interviewing (MI) condition, or standard care (STC) condition.
\end{abstract}

Methods: Three 24-h dietary recalls were completed at baseline and 6-months and were analyzed using NDS-R software; diet quality was assessed using the Healthy Eating Index-2010 (HEl-2010). Availability of foods and beverages in the home was assessed through direct observation using the Home Health Environment tool that classifies foods and beverages as 'red' or 'green' based upon fat and sugar content. Repeated measures linear mixed effects models were used to examine changes in diet quality and home food environment between conditions (LAUNCH, MI, STC).

Results: At 6-months, preschoolers in the LAUNCH condition had a higher HEl-2010 total score (62.8 \pm 13.7$)$ compared to preschoolers in the MI $(54.7 \pm 13.4, P=0.022)$ and STC $(55.8 \pm 11.6, P=0.046)$ conditions. Regarding the home food environment, families in LAUNCH had significantly less 'red' foods in their home at 6-months (12.5 \pm 3.4 'red' foods) compared to families in MI (14.0 \pm 3.7 'red' foods, $P=0.030)$, and STC (14.3 \pm 3.4 'red' foods, $P=0.006)$. There were no statistically significant differences across home food environments for number of 'green' foods.

Conclusion: Family-based obesity treatment interventions for preschoolers can improve overall diet quality and alter the home food environment through reductions in 'red' foods.

Trial registration: Clinicaltrials.gov, NCT01546727. Registered March 7, 2012.

Keywords: Family-based obesity treatment, Preschool nutrition, Home food environment, Healthy eating index

\section{Background}

Behavioral family-based obesity treatment interventions effectively intervene on energy balance behaviors to promote weight loss through energy intake reduction in children as young as 2-5years old [1-3]. Behavioral family-based obesity treatments use behavior modification strategies to alter parent feeding and child eating

\footnotetext{
* Correspondence: robson@udel.edu

${ }^{1}$ Department of Behavioral Health and Nutrition, University of Delaware, $26 \mathrm{~N}$ College Avenue, Newark, DE 19716, USA

Full list of author information is available at the end of the article
}

and physical activity patterns [2, 4]. Weight loss outcomes for up to 10 years have been reported for school age children who engaged in behavioral family-based obesity treatment [5]. However, it is unclear whether diet quality is also improving (an implicit goal of obesity treatment) or if children are simply eating less, but maintaining the same poor quality of diet [6]. Only one study of school age children (7-11 years-old) examined diet quality using the Healthy Eating Index (HEI) 2005 in a 16-week family-based obesity treatment intervention [7]. The HEI is a measure of adherence to the Dietary

(c) The Author(s). 2019 Open Access This article is distributed under the terms of the Creative Commons Attribution 4.0 International License (http://creativecommons.org/licenses/by/4.0/), which permits unrestricted use, distribution, and reproduction in any medium, provided you give appropriate credit to the original author(s) and the source, provide a link to the Creative Commons license, and indicate if changes were made. The Creative Commons Public Domain Dedication waiver (http://creativecommons.org/publicdomain/zero/1.0/) applies to the data made available in this article, unless otherwise stated. 
Guidelines for Americans based upon a scale of 0-100, with 100 demonstrating perfect adherence $[8,9]$. Scores of 50 or lower are considered to reflect a "poor" diet, scores 51-79 indicate the diet "needs improvement," and scores of 80 or greater reflect a "good" diet [10]. Altman and colleagues [7] found total HEI-2005 score improved from $59.3 \pm 8.8$ at baseline to $74.5 \pm 9.8$ post-treatment, indicating an improvement in overall diet quality over the 16-week period. This change was independent of changes in energy balance behaviors (energy intake and minutes of physical activity) and was associated with a reduction in eating foods away from home.

As pediatric obesity tracks across the life course [11-13], the early childhood years are considered a critical time to intervene on energy balance behaviors, especially diet, as children are hypothesized to be more susceptible to change during the preschool years [14]. During the preschool years, changes to energy balance through a reduction in energy intake can reduce obesity, which may prevent excess weight tracking into later childhood and adulthood [15]. In addition to weight management, the establishment of healthy eating behaviors during early childhood is also important due to the relationship between poor diet quality and other chronic diseases [16].

The current study conducted a secondary analysis examining change in diet quality for preschoolers enrolled in a randomized clinical trial where participants were assigned to a clinic and home-based behavioral, family-based obesity treatment program (LAUNCH), motivational interviewing (MI), or a standard care (STC) condition. Research has previously demonstrated that preschoolers receiving LAUNCH displayed a greater BMI z-score reduction compared to $\mathrm{MI}$ and STC; however, changes in diet quality between these groups have yet to be explored [1]. We hypothesized that diet quality, measured using the HEI-2010, would improve in preschoolers in the LAUNCH condition as compared to MI or STC.

As individual dietary intake is influenced by the home food environment, particularly the availability and accessibility of foods and beverages [17], family-based obesity treatments often recommend modifying the home food environment by adding or removing foods to encourage or discourage the consumption of these foods. However, few studies have assessed the home food environment of children undergoing a family-based obesity behavioral intervention and, therefore, the current study also examined changes in the home food environment for preschoolers participating in the clinical trial. We hypothesized that the home food environment would improve in the LAUNCH group with fewer 'red' foods defined as higher fat, high sugar foods and greater 'green' foods defined as lower fat, lower sugar foods in the home at 6-months.

\section{Methods \\ Participants}

From March 2012 to June 2015, preschoolers with obesity (BMI $\geq 95$ th percentile for age and sex) [18] were recruited through medical chart reviews from 27 independent pediatric practices and referrals from seven practices in a unified health system. Eligible children had a well-child visit within the last year and lived within 50 miles of the medical center where intervention sessions were conducted. Children were excluded if they had a medical condition (e.g., Prader-Willi syndrome) or were taking a medication that impacted weight (e.g., steroids); were participating in another weight management program, the caregiver or child had a medical condition or disability that would prevent participation in the program and/or physical activity (e.g., developmental delay); or the child or caregiver was non-English speaking. A total of 1629 children were invited/referred to participate, and 229 completed informed consent and were screened for eligibility. One hundred sixty-seven children met eligibility criteria and were randomized to a study condition; 151 met intent-to-treat criteria and were included in this analysis. Additional details regarding recruitment and enrollment of participants have been provided elsewhere [1]. The study protocol was approved by the Institutional Review Board at Cincinnati Children's Hospital Medical Center and was prospectively registered on clinical trials.gov (NCT01546727).

\section{Study design}

This study is a secondary analysis of data from a randomized clinical trial comparing LAUNCH, MI, and STC. The study conditions are described in brief below and full details are provided elsewhere $[19,20]$.

\section{Intervention \\ Launch}

LAUNCH is a 6-month, 18-session family-based obesity treatment program developed specifically for preschoolers that consisted of alternating clinical-based group sessions and individual home-based visits. Clinic sessions were $90-\mathrm{min}$ and were led by a clinical psychologist, and home-based visits were 60-min and were led by a postdoctoral fellow in psychology or nutrition, providing an intervention dose of $23 \mathrm{~h}$ over the 6 months. Caregivers were instructed to reduce their child's caloric intake to $1000 \mathrm{kcals} /$ day, $1200 \mathrm{kcals} /$ day, or $1400 \mathrm{kcals} /$ day depending upon their sex and age as recommended by the American Heart Association [21] and engage in $60 \mathrm{~min} /$ day of moderate-to-vigorous physical activity. As is standard in family-based behavioral obesity treatment programs, parents with a $\mathrm{BMI} \geq 25 \mathrm{~kg} / \mathrm{m}^{2}$ were also instructed to reduce calorie intake and engage in moderate-to-vigorous physical activity. Caregivers tracked 
dietary intake daily for themselves and their child. To assist with meeting calorie goals, parents and children were provided with information and skills to encourage purchasing and consumption of more 'green' foods and less 'red' foods.

\section{Motivational interviewing (MI)}

MI consisted of four in-person visits that were $60 \mathrm{~min}$ in length and 14 phone sessions (median phone session length was $15 \mathrm{~min}$ ) delivered at the same frequency as LAUNCH. Using the median phone session length MI provided a total intervention dose of $7.5 \mathrm{~h}$. During an initial session with a pediatrician, parents were provided with publicly available materials from the "Let's Go 5-2-1-0" program. Subsequent sessions were conducted by a licensed clinical psychologist and followed the tenets of MI related to caregiver concern about the child's weight, diet, and/or physical activity behaviors. Caregivers were presented a menu of target dietary and physical activity behaviors (i.e. increasing fruit and vegetable intake, decreasing screen time). Sessions were caregiver-driven behavioral changes with the therapist supporting problem-solving or providing information as requested.

\section{Standard care (STC)}

Families randomized to STC did not receive any treatment (0 contact hours) through the current study beyond being informed their child met criteria for obesity during the recruitment process.

\section{Measures}

\section{Demographics}

Caregivers completed a self-report questionnaire regarding family, caregiver, and child demographics.

\section{Dietary intake}

Three random 24-h dietary recalls (2 weekdays and 1 weekend day), using the multiple pass method were conducted by trained Registered Dietitians blinded to treatment condition. The first dietary recall was conducted in person at the baseline visit with the two subsequent dietary recalls completed over the phone at unannounced times. For children who attended childcare $(72.2 \%$ at baseline), with parent permission the Registered Dietitian called the childcare center to assess dietary intake. If the childcare center could not be contacted directly parents were instructed to have the childcare providers record what the child ate with paper and pencil daily until the two recalls were completed. Dietary recalls were analyzed using Nutrition Data Systems for Research software (versions 2012-2016, Nutrition Coordinating Center, University of Minnesota) to obtain average daily energy intake and servings from food groups (fruits and vegetables, sugar sweetened beverages, sweet and salty snack foods). The HEI-2010 was used to assess dietary quality. The HEI-2010 is a measure of adherence to the 2010 Dietary Guidelines for Americans and is derived from 12 components, including 9 adequacy components (total fruit, whole fruit, total vegetables, greens and beans, whole grains, dairy, total protein foods, seafood and plant proteins, and fatty acids) and 3 moderation components (refined grains, sodium, and empty calories). Higher scores for each component represent better diet quality with moderation components being reverse scored. Total HEI-2010 score can theoretically range from 0 to 100 , with 100 indicating perfect adherence. Given when data were collected HEI-2010 was used, which is similar to HEI-2005 and the new HEI-2015. All versions are reflective of the Dietary Guidelines for Americans at that time and include adequacy and moderation components, and used a density approach to set standards. Several differences do exist between HEI-2005 and HEI-2010, specifically related to the components in regards to how they were defined and/or the standards for minimum/maximum points, and have been outlined by the National Cancer Institute [22].

\section{Home food environment}

The availability of foods and beverages in the home was assessed using the Home Health Environment, a direct observation tool [23]. The availability (yes/no) of foods (candy; prepared baked goods; baking items; chips, pretzels, popcorn and rice cakes; crackers; fruit roll-ups or fruit snacks; granola bars, breakfast bars and toaster strudels; dried fruit; cereal; pasta mixes; bread; meat; frozen foods; ice cream or frozen desserts; cheese, yogurt and cottage cheese; syrups) and beverages (100\% fruit juice; fruit drinks; regular sodas; diet sodas; sport drinks; powdered drinks; milk) was recorded. Availability (yes/no) of fresh, frozen, and canned fruits and vegetables was also recorded. Foods, beverages and canned fruits were coded as 'green' or 'red' foods based upon fat and sugar content. Foods/beverages were summed across categories to obtain a total frequency of 'red' foods/beverages and 'green' foods/beverages (including fresh, frozen and canned fruits and vegetables). Total frequency of fresh, frozen and canned fruits and vegetables was also analyzed. A trained observer blinded to the families' treatment assignment conducted all assessments of the home food environment. Twenty-six percent of randomly selected homes had a second independent observer code the home food environment for inter-rater reliability (IRR) with excellent reliability for all food and beverage categories ( $R R \geq 0.95$ ). 


\section{Statistical analysis}

Descriptive statistics were computed for the group as a whole as well as by condition. Measures of central tendency, variability, and association were computed for all relevant treatment-related variables. All tests were conducted using alpha $=0.05$, and summary measures are presented as mean \pm standard deviation. A repeated measures linear mixed effects model was used to examine changes in the primary outcome variables diet quality (as measured by HEI-2010 total score), and 'red' foods and 'green' foods in the home food environment, and secondary outcome dietary intake variables (energy intake, food group servings) and home food environment variables (fruits, vegetables, fruits and vegetables) across the two study time points (baseline and 6-months) comparing the three conditions (LAUNCH, MI and STC) accounting for the correlation between measures on the same subject by directly modeling the covariance structure of the residuals as unstructured. For energy intake, models were adjusted for age, sex, and baseline body weight. Tests for mean differences were conducted using the Kenward-Roger approximation for the degrees of freedom; $p$-values comparing the mean responses between time points were adjusted for multiple comparisons using the Tukey-Kramer method [24]. All statistical analyses were performed using SAS software, Version 9.4 (SAS Institute, Cary, NC).

\section{Results}

Participants were 151 preschoolers $(55.1 \pm 11.2$ months) who met criteria for obesity (BMI percentile: $98.6 \pm 1.3$; BMI z-score: $2.4 \pm 0.6)$. Children were $57 \%$ female, predominantly White (76\%) and non-Hispanic (94\%) and participated with one designated caregiver, who were primarily mothers $(90 \%)$. Caregivers were most likely to be married $(72 \%)$, have a college degree (53\%) and have obesity $(67 \%)$ defined as a BMI $\geq 30 \mathrm{~kg} / \mathrm{m}^{2}$. At baseline, demographics and anthropometrics were not significantly different between conditions. See Table 1 for complete participant demographics.

\section{Dietary intake}

There was a significant $(P=0.007)$ condition by time interaction for HEI-2010. At 6-months, HEI-2010 total score was significantly higher in LAUNCH $(62.8 \pm 13.7)$ as compared to MI $(54.7 \pm 13.4, P=0.022)$, and STC (55.8 $\pm 11.6, P=0.046)$. Overall, children had a HEI-2010 total score of $56.6 \pm 10.7$ at baseline $(n=151)$ and $57.7 \pm$ 13.3 at 6 -months $(n=135)$. Analyses for HEI component scores are shown in Table 2.

There was a significant $(P<0.001)$ condition by time interaction for energy intake. At 6-months LAUNCH $(1147.8 \pm 216.5 \mathrm{kcals})$ had a significantly lower mean energy intake as compared to MI $(1410.6 \pm 333.6 \mathrm{kcals}$,
$P<0.001)$ and STC $(1408.8 \pm 337.1$ kcals, $P<0.001)$. The reduction in energy intake corresponds with the main outcomes of the primary study demonstrated LAUNCH had a significantly greater decrease in BMI z-score $(-0.32 \pm 0.33)$ as compared with MI $(-0.05 \pm$ $0.27, P<0.001)$ and compared with STC $(-0.13 \pm$ $0.31, P<0.004)[1]$.

There was not a significant time by condition interaction for consumption of servings of fruits and vegetables, but at 6 -months children in LAUNCH consumed significantly more servings of fruits and vegetables ( $2.8 \pm 1.7$ servings) as compared to STC $(2.0 \pm 1.0$ servings, $P=0.040)$. When servings of fruits and vegetables were examined separately there was a significant $(P=0.040)$ condition by time interaction for fruit, but not for vegetables. At 6-months children in LAUNCH consumed significantly more servings of fruit $(1.7 \pm 1.2$ servings) as compared to STC (0.9 \pm 0.7 servings, $P<0.001)$, but not MI $(1.5 \pm 1.3$ servings, $P=0.366)$. Sugar sweetened beverage intake and sweet and salty snack foods also had a significant time by condition interactions. At 6-months children in LAUNCH consumed significantly fewer servings of sugar sweetened beverages ( $0.3 \pm 0.4$ servings $)$ as compared to MI $(0.7 \pm 0.6$ servings, $P=0.005)$, and STC $(0.9 \pm 1.0$ servings, $P<0.001)$. Similarly, children in LAUNCH consumed fewer servings $(1.3 \pm 0.8$ servings) of sweet and salty snack foods at 6 -months as compared to $\mathrm{MI}(1.9 \pm 1.4$ servings, $P=0.040)$, but not STC $(1.8 \pm 1.4$ servings, $P=0.131)$.

\section{Home food environment}

As shown in Table 3, across all conditions there was a significant condition by time interaction $(P<0.001)$ for 'red' foods in the home. At 6-months, families in LAUNCH had significantly less 'red' foods in their home $(12.5 \pm 3.4$ 'red' foods) as compared to families in MI $(14.0 \pm 3.7$ 'red' foods, $P=0.030)$ and STC $(14.3 \pm 3.4$ 'red' foods, $P=0.006$ ). There was not a significant main effect of time, condition or a significant time by condition interaction for 'green' foods, fruits, or vegetables.

\section{Discussion}

LAUNCH, a behavioral family-based obesity treatment delivered through clinic and home-based sessions, resulted in lower energy intake and also higher overall diet quality at 6-months as compared to MI and STC conditions. Consistent with the literature reporting the poor quality of preschool children's diet, preschool children enrolled in this study had overall diet quality at baseline that needed improvement with a mean HEI total score of $56.6 \pm 10.7$ mirroring scores reported for preschool-aged children nationally 55.3 (95\% CI: 53.6, 57.0) [6]. While children receiving LAUNCH had a statistically 
Table 1 Baseline demographic and anthropometrics characteristics of preschool children enrolled in a family-based obesity treatment intervention

\begin{tabular}{|c|c|c|c|c|}
\hline & $\begin{array}{l}\text { Overall } \\
n=151\end{array}$ & $\begin{array}{l}\text { LAUNCH } \\
n=47\end{array}$ & $\begin{array}{l}\mathrm{Ml} \\
n=50\end{array}$ & $\begin{array}{l}\text { STC } \\
n=54\end{array}$ \\
\hline Child Age (months), $\mathrm{M} \pm \mathrm{SD}$ & $55.1 \pm 11.2$ & $55.1 \pm 12.1$ & $55.0 \pm 10.7$ & $55.3 \pm 11.1$ \\
\hline \multicolumn{5}{|l|}{ Child Sex n (\%) } \\
\hline Male & $65(43.0 \%)$ & $22(46.8 \%)$ & $21(42.0 \%)$ & $22(40.7 \%)$ \\
\hline Female & $86(57.0 \%)$ & $25(53.2 \%)$ & $29(58.0 \%)$ & $32(59.3 \%)$ \\
\hline \multicolumn{5}{|l|}{ Child Ethnicity n (\%) } \\
\hline Hispanic or Latino & $9(6.0 \%)$ & $1(2.1 \%)$ & $3(6.0 \%)$ & $5(9.3 \%)$ \\
\hline Non-Hispanic & $142(94.0 \%)$ & $46(97.9 \%)$ & $47(94.0 \%)$ & 49 (90.7\%) \\
\hline \multicolumn{5}{|l|}{ Child Race $n(\%)$} \\
\hline Black & $14(9.3 \%)$ & $3(6.4 \%)$ & $6(12.0 \%)$ & $5(9.3 \%)$ \\
\hline White & $115(76.2 \%)$ & $37(78.7 \%)$ & 38 (76.0\%) & $40(74.1 \%)$ \\
\hline More Than One Race/Other & $22(14.6 \%)$ & 7 (14.9\%) & $6(12.0 \%)$ & $9(16.7 \%)$ \\
\hline Child BMI M \pm SD & $20.9 \pm 2.5$ & $20.9 \pm 2.5$ & $20.7 \pm 2.4$ & $21.0 \pm 2.6$ \\
\hline Child BMI Z-score $\mathrm{M} \pm \mathrm{SD}$ & $2.44 \pm 0.60$ & $2.41 \pm 0.53$ & $2.41 \pm 0.56$ & $2.48 \pm 0.70$ \\
\hline Child BMI Percentile M \pm SD & $98.6 \pm 1.3$ & $98.6 \pm 1.2$ & $98.5 \pm 1.3$ & $98.6 \pm 1.3$ \\
\hline \multicolumn{5}{|l|}{ Family Income $n(\%)$} \\
\hline$<\$ 30 k$ & $16(10.6 \%)$ & $4(8.5 \%)$ & $8(16.0 \%)$ & $4(7.4 \%)$ \\
\hline$\$ 30 k-49.9 k$ & $23(15.2 \%)$ & $9(19.2 \%)$ & $5(10.0 \%)$ & $9(16.7 \%)$ \\
\hline$\$ 50 k-99.9 k$ & $77(51.0 \%)$ & $25(53.2 \%)$ & $23(46.0 \%)$ & $29(53.7 \%)$ \\
\hline$\geq \$ 100 k$ & $34(22.5 \%)$ & $9(19.2 \%)$ & $14(28.0 \%)$ & $11(20.4 \%)$ \\
\hline Not Reported & $1(0.7 \%)$ & $0(0.0 \%)$ & $0(0.0 \%)$ & $1(1.9 \%)$ \\
\hline Hollingshead Score ${ }^{1} \mathrm{M} \pm \mathrm{SD}$ & $43.0 \pm 11.7$ & $43.2 \pm 11.1$ & $42.2 \pm 12.7$ & $43.6 \pm 11.3$ \\
\hline
\end{tabular}

significant improvement in mean HEI-2010 total score from $56.2 \pm 11.0$ at baseline to $62.8 \pm 13.7$ at 6-months, their overall diet quality as measured by HEI continued to be in the "needs improvement" category (scores of 51-79) [10]. The ability of behavioral family-based obesity treatment programs to reduce energy intake and improve overall diet quality is promising and may provide benefits for chronic disease prevention beyond obesity. While chronic disease associated with poor dietary intake is not often present in preschool-aged children due to the limited time for disease progression, in adults higher diet quality scores have been associated with lower risk of cardiovascular disease and cancer [25-27].

In preschool children, changes to specific food groups (e.g. fruits and vegetables) have not been found to significantly predict changes in BMI z-score [15]. However, data from several studies indicate a reduction in higher calorie, lower nutrient ('red') foods appear to be a stronger underlying mechanism of weight change outcomes as compared to changes in lower calorie, higher nutrient ('green') foods. In 7-12 year-old children participating in a family-based obesity treatment, Best and colleagues
[28] found long-term change in self-reported 'red' food intake predicted children's weight loss maintenance while change in fruits and vegetables did not. Data from the current study support this notion as changes in categories associated with higher calorie, lower nutrient dietary intake (e.g. discretionary calories, servings of sugar sweetened beverages, servings of sweet and salty snack foods, 'red' foods) were significant while changes in lower calorie, higher nutrient foods (e.g. fruits and vegetables, 'green' foods) were not.

While reductions in high calorie, low nutrient foods may be more strongly associated with reductions in energy intake, it appears these foods are not replaced with high nutrient, low calorie foods [29, 30]. Golley and colleagues [31] found a reduction in high calorie, low nutrient foods in 6-9 year-old children participating in a 6-month weight management program in Australia, but intake of fruits and vegetables was unchanged. While this specific relationship was not analyzed, children enrolled in LAUNCH had significant dietary changes across high calorie, low nutrient (e.g. sweet and salty snack foods, sugar sweetened beverages) and low calories, high nutrient food groups (e.g. fruits and 
Table 2 Changes in energy intake, dietary quality and servings of food groups in preschool children enrolled in a family-based obesity treatment intervention ${ }^{1}$

\begin{tabular}{|c|c|c|c|c|c|c|}
\hline & LAUNCH $^{1}$ & $\mathrm{Ml}^{1}$ & $\mathrm{STC}^{1}$ & Condition $^{2}$ & Time $^{2}$ & Condition $\times$ Time $^{2}$ \\
\hline \multicolumn{4}{|c|}{ Energy Intake ${ }^{3}$} & 0.058 & $<0.001^{* * *}$ & $<0.001^{* * *}$ \\
\hline Baseline & $1455.6 \pm 300.6$ & $1425.0 \pm 356.2$ & $1323.0 \pm 273.8$ & & & \\
\hline 6 months & $1147.8 \pm 216.5$ & $1410.6 \pm 333.6$ & $1408.8 \pm 337.1$ & & & \\
\hline \multicolumn{4}{|c|}{ HEl-2010 total score [0-100] } & 0.147 & 0.212 & $0.007^{* *}$ \\
\hline Baseline & $56.2 \pm 11.0$ & $55.6 \pm 9.7$ & $57.9 \pm 11.4$ & & & \\
\hline 6 months & $62.8 \pm 13.7$ & $54.7 \pm 13.4$ & $55.8 \pm 11.6$ & & & \\
\hline \multicolumn{4}{|c|}{ Total Fruit [0-5] } & 0.245 & 0.972 & 0.094 \\
\hline Baseline & $3.5 \pm 1.6$ & $3.2 \pm 1.7$ & $3.3 \pm 1.9$ & & & \\
\hline 6 months & $3.7 \pm 1.7$ & $3.3 \pm 1.7$ & $2.8 \pm 1.6$ & & & \\
\hline \multicolumn{4}{|c|}{ Whole Fruit [0-5] } & 0.234 & 0.210 & 0.236 \\
\hline Baseline & $3.5 \pm 1.8$ & $3.7 \pm 1.6$ & $3.3 \pm 1.9$ & & & \\
\hline 6 months & $4.1 \pm 1.4$ & $3.7 \pm 1.7$ & $3.2 \pm 1.7$ & & & \\
\hline \multicolumn{4}{|c|}{ Total Vegetables [0-5] } & 0.051 & $0.045^{*}$ & $0.010^{*}$ \\
\hline Baseline & $2.8 \pm 1.5$ & $2.8 \pm 1.5$ & $3.2 \pm 1.5$ & & & \\
\hline 6 months & $3.7 \pm 1.5$ & $2.6 \pm 1.6$ & $3.4 \pm 1.4$ & & & \\
\hline \multicolumn{4}{|c|}{ Greens and Beans [0-5] } & 0.770 & $0.002^{* *}$ & 0.379 \\
\hline Baseline & $0.5 \pm 1.3$ & $0.7 \pm 1.4$ & $0.6 \pm 1.2$ & & & \\
\hline 6 months & $1.4 \pm 1.9$ & $0.9 \pm 1.6$ & $0.9 \pm 1.6$ & & & \\
\hline \multicolumn{4}{|c|}{ Whole Grains [0-10] } & 0.422 & $0.026^{*}$ & 0.127 \\
\hline Baseline & $3.7 \pm 3.0$ & $3.9 \pm 2.9$ & $3.4 \pm 3.0$ & & & \\
\hline 6 months & $5.1 \pm 3.3$ & $3.8 \pm 3.4$ & $4.0 \pm 3.0$ & & & \\
\hline \multicolumn{4}{|l|}{ Dairy [0-10] } & $0.045^{*}$ & 0.782 & 0.502 \\
\hline Baseline & $9.4 \pm 1.3$ & $8.7 \pm 2.1$ & $8.6 \pm 2.2$ & & & \\
\hline 6 months & $9.3 \pm 1.8$ & $8.7 \pm 2.2$ & $8.9 \pm 1.8$ & & & \\
\hline \multicolumn{4}{|c|}{ Total Protein Foods [0-5] } & 0.458 & 0.758 & $0.003^{* *}$ \\
\hline Baseline & $3.6 \pm 1.3$ & $4.1 \pm 1.3$ & $4.0 \pm 1.2$ & & & \\
\hline 6 months & $4.2 \pm 1.2$ & $3.5 \pm 1.4$ & $4.1 \pm 1.1$ & & & \\
\hline \multicolumn{4}{|c|}{ Seafood and Plant Proteins [0-5] } & 0.997 & 0.785 & $0.027^{*}$ \\
\hline Baseline & $1.3 \pm 1.7$ & $2.0 \pm 2.1$ & $2.0 \pm 2.0$ & & & \\
\hline 6 months & $2.2 \pm 2.2$ & $1.5 \pm 1.9$ & $1.4 \pm 1.9$ & & & \\
\hline \multicolumn{4}{|c|}{ Fatty Acids [0-10] } & 0.128 & 0.550 & 0.164 \\
\hline Baseline & $3.4 \pm 3.0$ & $3.3 \pm 3.0$ & $4.0 \pm 3.1$ & & & \\
\hline 6 months & $4.2 \pm 3.0$ & $2.7 \pm 2.2$ & $3.2 \pm 2.9$ & & & \\
\hline \multicolumn{4}{|c|}{ Sodium [0-10] } & 0.132 & 0.073 & $<0.001^{* * *}$ \\
\hline Baseline & $4.4 \pm 2.5$ & $3.4 \pm 2.7$ & $4.8 \pm 2.9$ & & & \\
\hline 6 months & $2.6 \pm 2.4$ & $4.6 \pm 3.1$ & $3.8 \pm 2.6$ & & & \\
\hline \multicolumn{4}{|c|}{ Refined Grains [0-10] } & 0.694 & 0.118 & 0.333 \\
\hline Baseline & $5.5 \pm 3.5$ & $6.2 \pm 2.8$ & $6.3 \pm 3.2$ & & & \\
\hline 6 months & $5.5 \pm 3.6$ & $5.2 \pm 2.8$ & $5.7 \pm 3.2$ & & & \\
\hline \multicolumn{4}{|c|}{ Empty Calories [0-20] } & $0.007^{* *}$ & $0.022^{*}$ & $0.012^{*}$ \\
\hline Baseline & $14.7 \pm 4.1$ & $13.7 \pm 4.2$ & $14.3 \pm 3.5$ & & & \\
\hline 6 months & $17.0 \pm 3.3$ & $14.0 \pm 3.9$ & $14.2 \pm 4.3$ & & & \\
\hline
\end{tabular}


Table 2 Changes in energy intake, dietary quality and servings of food groups in preschool children enrolled in a family-based obesity treatment intervention ${ }^{1}$ (Continued)

\begin{tabular}{|c|c|c|c|c|c|c|}
\hline & $\mathrm{LAUNCH}^{1}$ & $\mathrm{Ml}^{1}$ & $\mathrm{STC}^{1}$ & Condition $^{2}$ & Time $^{2}$ & Condition $\times$ Time $^{2}$ \\
\hline \multicolumn{4}{|c|}{ Servings of FVs } & 0.168 & $0.009^{* *}$ & 0.119 \\
\hline Baseline & $2.1 \pm 1.4$ & $2.0 \pm 1.2$ & $2.0 \pm 1.2$ & & & \\
\hline 6 months & $2.8 \pm 1.7$ & $2.4 \pm 1.6$ & $2.0 \pm 1.0$ & & & \\
\hline \multicolumn{4}{|c|}{ Servings of Fruits } & $0.012^{*}$ & 0.114 & $0.040^{*}$ \\
\hline Baseline & $1.3 \pm 1.1$ & $1.2 \pm 0.9$ & $1.1 \pm 0.9$ & & & \\
\hline 6 months & $1.7 \pm 1.2$ & $1.5 \pm 1.3$ & $0.9 \pm 0.7$ & & & \\
\hline \multicolumn{4}{|c|}{ Servings of Vegetables } & 0.574 & $0.016^{*}$ & 0.524 \\
\hline Baseline & $0.8 \pm 0.6$ & $0.8 \pm 0.7$ & $0.9 \pm 0.7$ & & & \\
\hline 6 months & $1.1 \pm 0.8$ & $0.9 \pm 0.9$ & $1.1 \pm 0.8$ & & & \\
\hline \multicolumn{4}{|c|}{ Servings of SSB } & $0.011^{*}$ & $0.022^{*}$ & $0.003^{* *}$ \\
\hline Baseline & $0.7 \pm 0.7$ & $1.0 \pm 1.2$ & $0.8 \pm 0.7$ & & & \\
\hline 6 months & $0.3 \pm 0.4$ & $0.7 \pm 0.6$ & $0.9 \pm 1.0$ & & & \\
\hline \multicolumn{4}{|c|}{ Servings of SSS } & 0.465 & 0.216 & $0.033^{*}$ \\
\hline Baseline & $1.9 \pm 1.3$ & $1.8 \pm 1.1$ & $1.7 \pm 1.0$ & & & \\
\hline 6 months & $1.3 \pm 0.8$ & $1.9 \pm 1.4$ & $1.8 \pm 1.4$ & & & \\
\hline
\end{tabular}

${ }^{1}$ Values are raw data means \pm SDs. At baseline $\mathrm{LAUNCH}, n=47 ; \mathrm{Ml}, n=50 ; \mathrm{STC}, n=54$ and at 6 months LAUNCH, $n=43 ; \mathrm{MI}=44 ; \mathrm{STC}=48$. ${ }^{2}$ Values are $P$-values ${ }^{3}$ Energy intake is adjusted for sex, age, and baseline weight

HEl-2010 = Healthy Eating Index - 2010; FVs = fruits and vegetables; SSB = sugar sweetened beverages; SSS = sweet and salty snack foods ${ }^{*} P<0.05 ;{ }^{* *} P<0.01 ;{ }^{* *} P<0.001$

vegetables), but only when compared to STC and not when compared to MI. Individual dietary intake changes were small, in the amount of approximately a 1/4-cup equivalent; however, they were adequate enough to reduce energy intake and improve dietary quality.
In addition to changes in child dietary intake, we found similar findings in the home food environment. The home environment has been identified as an important mediator of improved outcomes during family-based obesity treatment [32]. Study pilot data

Table 3 Frequency of foods in the home food environment of preschool children with obesity enrolled in a family-based obesity treatment intervention

\begin{tabular}{|c|c|c|c|c|c|c|}
\hline & $\mathrm{LAUNCH}^{1}$ & $\mathrm{Ml}^{1}$ & $\mathrm{STC}^{1}$ & Condition $^{2}$ & Time $^{2}$ & Condition $\times$ Time \\
\hline 'Red' Foods & & & & 0.170 & $<0.001^{* * *}$ & $<0.001^{* * *}$ \\
\hline Baseline & $15.3 \pm 3.4$ & $14.4 \pm 4.7$ & $15.6 \pm 3.4$ & & & \\
\hline 6 months & $12.5 \pm 3.4$ & $14.0 \pm 3.7$ & $14.3 \pm 3.4$ & & & \\
\hline 'Green' Foods & & & & 0.340 & 0.495 & 0.069 \\
\hline Baseline & $24.6 \pm 8.3$ & $23.8 \pm 8.2$ & $25.4 \pm 7.2$ & & & \\
\hline 6 months & $26.8 \pm 8.1$ & $22.8 \pm 7.7$ & $24.2 \pm 8.1$ & & & \\
\hline Fruits & & & & 0.800 & 0.443 & 0.603 \\
\hline Baseline & $6.0 \pm 3.0$ & $5.9 \pm 3.0$ & $5.9 \pm 3.2$ & & & \\
\hline 6 months & $6.4 \pm 3.0$ & $5.6 \pm 3.2$ & $5.8 \pm 3.3$ & & & \\
\hline Vegetables & & & & 0.407 & 0.330 & 0.123 \\
\hline Baseline & $10.6 \pm 4.6$ & $10.2 \pm 4.4$ & $10.8 \pm 4.8$ & & & \\
\hline 6 months & $11.5 \pm 4.6$ & $9.4 \pm 4.0$ & $10.2 \pm 4.8$ & & & \\
\hline FVs & & & & 0.500 & 0.234 & 0.148 \\
\hline Baseline & $16.6 \pm 6.7$ & $16.2 \pm 6.3$ & $16.7 \pm 6.6$ & & & \\
\hline 6 months & $17.8 \pm 6.9$ & $15.0 \pm 5.9$ & $15.9 \pm 7.2$ & & & \\
\hline
\end{tabular}

${ }^{1}$ Values are raw data means \pm SDs. At baseline $\mathrm{LAUNCH}, n=47 ; \mathrm{MI}, n=50 ; \mathrm{STC}, n=54$ and at 6 months $\mathrm{LAUNCH}, n=43 ; \mathrm{MI}=44 ; \mathrm{STC}=48 .{ }^{2} \mathrm{Values}$ are $P$-values $\mathrm{FVs}=$ fruits and vegetables

${ }^{*} P<0.05 ;{ }^{* *} P<0.01 ;{ }^{* * *} P<0.001$ 
demonstrated that a family-based obesity treatment with home visitation resulted in significant increases in available servings of fruits and vegetables and decreased high-calorie foods in the home food environment as compared to pediatric counseling [33]. The LAUNCH condition, which included home visitation, similarly found a significant reduction in 'red' foods; however, in contrast to our pilot study, availability of fruits and vegetables did not increase significantly despite an increase in consumption of servings in the LAUNCH condition and decreases in the MI and STC condition.

The current study has several strengths, particularly the strong assessment measures including multiple 24-h recalls conducted by Registered Dietitians blinded to treatment assignment and the use of direct observation home food environment assessment based upon open inventory methodology where all foods and beverages available are recorded. Assessing data at both the individual and home food environment level may strengthen findings related to dietary outcomes, but further investigation would be needed to evaluate concordance between measures. Findings need to be interpreted within the context of study limitations. Intervention dose between conditions was different as designed given the primary study specifically compared LAUNCH to STC and LAUNCH to MI. Given this study compared between conditions, findings in the LAUNCH condition could be influenced by the greater intervention dose received by families as compared to MI and STC. Dietary data were self-reported by caregivers of children, and may be limited to the recall memory of caregiver, but also be subject to self-report bias. While the Home Food Environment tool has not been validated it was been previously used [23] and $26 \%$ of homes had a second independent observer to demonstrate inter-rater reliability. Furthermore, the sample was treatment-seeking families of preschoolers with obesity from primarily White, high-income, two-parent households, which may limit generalizability to other populations.

\section{Conclusions}

As hypothesized LAUNCH had a greater improvement in diet quality as measured by HEI-2010 score, and a greater decrease in 'red' foods in the home food environment as compared to MI and STC. However, contrary to our hypothesis there was not a significant increase in 'green' foods in the home food environment in the LAUNCH condition. While the improvement in diet quality was encouraging, these changes did not move the children into the "good" range for diet quality on the HEI; this may indicate that additional attention should be focused on diet quality in the context of weight management programs for preschoolers. To have an impact on diet quality and the home food environment outcomes from this study suggest a stronger focus on reducing high calorie, low nutrient foods (e.g. SSBs, SSS) instead of increasing lower calorie, higher nutrient foods (e.g. fruits, vegetables) will be most beneficial.

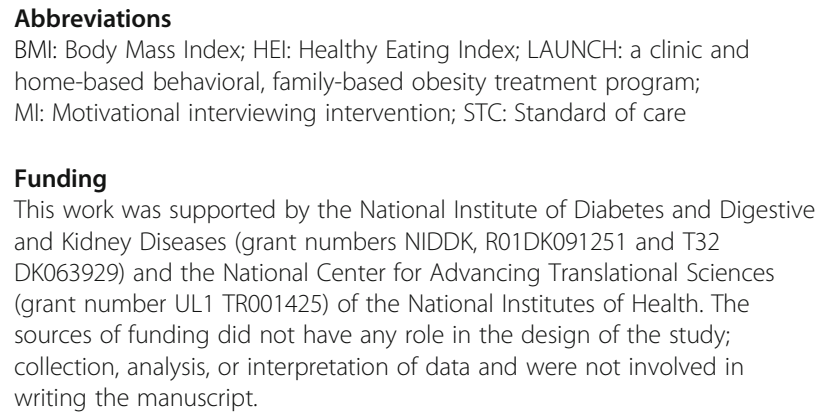

\section{Funding}

This work was supported by the National Institute of Diabetes and Digestive and Kidney Diseases (grant numbers NIDDK, R01DK091251 and T32 DK063929) and the National Center for Advancing Translational Sciences (grant number UL1 TR001425) of the National Institutes of Health. The sources of funding did not have any role in the design of the study; collection, analysis, or interpretation of data and were not involved in writing the manuscript.

\section{Availability of data and materials}

The datasets used and/or analyzed during the current study are available from the corresponding author on reasonable request.

\section{Authors contributions}

LJS and CZ designed research; LS, CZ, SMR, MC, COS, and SS conducted research; MZ and RI analyzed data; SMR and MZ wrote the paper and had primary responsibility of the final content. All authors read and approved the final manuscript.

\section{Ethics approval and consent to participate}

The study protocol was approved by the Institutional Review Board at Cincinnati Children's Hospital Medical Center. Informed consent was obtained from the participating child's parent or legal guardian before any data were collected.

\section{Consent for publication \\ Not applicable.}

\section{Competing interests}

The authors declare that they have no competing interests.

\section{Publisher's Note}

Springer Nature remains neutral with regard to jurisdictional claims in published maps and institutional affiliations.

\section{Author details}

'Department of Behavioral Health and Nutrition, University of Delaware, $26 \mathrm{~N}$ College Avenue, Newark, DE 19716, USA. 'Biostatistics Core, College of Health Sciences, University of Delaware, 540 S. College Avenue, Newark, DE 19713, USA. ${ }^{3}$ Psychology Department, Suffolk University, 73 Tremont Street, Boston, MA 02108, USA. ${ }^{4}$ Department of Psychology, University of Cincinnati, 47 W Corry Blvd Edwards 1 Bldg Suite 4130, P.O. Box 210376, Cincinnati, OH 45219, USA. ${ }^{5}$ Division of Behavioral Medicine and Clinical Psychology,

Cincinnati Children's Hospital Medical Center, 3333 Burnet Avenue MLC 3015, Cincinnati, OH 45229, USA. ${ }^{6}$ Department of Pediatrics, Division of Pulmonary Medicine, University of Colorado Anschutz Medical Campus and Children's Hospital Colorado, 13123 E 16th Ave B395 Aurora, Aurora, CO 80045, USA. ${ }^{7}$ Department of Pediatrics, University of Cincinnati College of Medicine, 3230 Eden Ave, Cincinnati, OH 45267, USA. ${ }^{8}$ Division of Biostatistics and Epidemiology, Cincinnati Children's Hospital Medical Center, 3333 Burnet Avenue MLC 5041, Cincinnati, OH 45229, USA.

Received: 8 September 2018 Accepted: 30 January 2019

Published online: 04 February 2019

\section{References}

1. Stark LJ, Spear Filigno S, Bolling C, Ratcliff MB, Kichler JC, Robson SM, et al. Clinic and home-based behavioral intervention for obesity in preschoolers: a randomized trial. J Pediatr. 2018;192:115-21. 
2. US Preventive Services Task Force, Grossman DC, Bibbins-Domingo K, Curry SJ, Barry MJ, Davidson KW, et al. Screening for obesity in children and adolescents: US Preventive Services Task Force recommendation statement. JAMA. 2017:317(23):2417-26.

3. van Hoek E, Feskens EJ, Bouwman LI, Janse AJ. Effective interventions in overweight or obese young children: systematic review and meta-analysis. Child Obes. 2014;10(6):448-60.

4. Colquitt IL, Loveman E, O'Malley C, Azevedo LB, Mead E, Al-Khudairy L, et al. Diet, physical activity, and behavioural interventions for the treatment of overweight or obesity in preschool children up to the age of 6 years. Cochrane Database Syst Rev. 2016;3:CD012105.

5. Epstein L, Valoski A, Wing R, McCurley J. Ten-year-outcomes of behavioral family-based treatment for childhood obesity. Health Psychol. 1994;13:373-83.

6. Gu X, Tucker KL. Dietary quality of the US child and adolescent population: trends from 1999 to 2012 and associations with the use of federal nutrition assistance programs. Am J Clin Nutr. 2017;105(1):194-202.

7. Altman M, Cahill Holland J, Lundeen D, Kolko RP, Stein RI, Saelens BE, et al. Reduction in food away from home is associated with improved child relative weight and body composition outcomes and this relation is mediated by changes in diet quality. J Acad Nutr Diet. 2015;115(9):1400-7.

8. Guenther PM, Kirkpatrick SI, Reedy J, Krebs-Smith SM, Buckman DW, Dodd KW, et al. The healthy eating Index-2010 is a valid and reliable measure of diet quality according to the 2010 dietary guidelines for Americans. J Nutr. 2014;144(3):399-407.

9. Guenther P, Casavale K, Reedy J, Kirkpatrick SI, Hiza HA, Kuczynski KJ, et al. Update of the healthy eating index: HEl-2010. J Am Diet Assoc. 2013;113(4):569-80.

10. Snetselaar L. Are Americans following US dietary guidelines? Check the Healthy Eating Index. Elsevier Connect [Internet]. 2015; Available from: https://www.elsevier.com/connect/are-americans-following-us-dietaryguidelines-check-the-healthy-eating-index

11. Cunningham SA, Kramer MR, Narayan KM. Incidence of childhood obesity in the United States. N Engl J Med. 2014;370(5):403-11.

12. Freedman DS, Khan LK, Serdula MK, Dietz WH, Srinivasan SR, Berenson GS. The relation of childhood BMI to adult adiposity: the Bogalusa heart study. Pediatrics. 2005;115(1):22-7.

13. Guo SS, Chumlea WC. Tracking of body mass index in children in relation to overweight in adulthood. Am J Clin Nutr. 1999;70(1):145S-8S.

14. American Heart Association. Policy Recommendations for Obesity Prevention in Early Care and Education Setting. [Internet]. 2015. Available from: https://www.heart.org/idc/groups/heart-public/@wcm/@adv/ documents/downloadable/ucm_473791.pdf.

15. Kuhl ES, Clifford LM, Bandstra NF, Filigno SS, Yeomans-Maldonado G, Rausch $\mathrm{JR}$, et al. Examination of the association between lifestyle behavior changes and weight outcomes in preschoolers receiving treatment for obesity. Health Psychol. 2014;33(1):95-8.

16. Bauer UE, Briss PA, Goodman RA, Bowman BA. Prevention of chronic disease in the 21st century: elimination of the leading preventable causes of premature death and disability in the USA. Lancet. 2014;384(9937):45-52.

17. Birch LL, Davison KK. Family environmental factors influencing the developing behavioral controls of food intake and childhood overweight. Pediatr Clin N Am. 2001;48(4):893-907.

18. Kuczmarski R, Ogden C, Guo S, Grummer-Strawn L, Flegal K, Mei Z, et al. CDC growth charts for the United States: methods and development. Vital health stat 11. 2002. 2000;246:1-190.

19. Stark LJ, Filigno SS, Bolling C, Ratcliff MB, Kichler JC, Robson SL, et al. Learning about activity and understanding nutrition for child health (LAUNCH): rationale, design, and implementation of a randomized clinical trial of a family-based pediatric weight management program for preschoolers. Contemp Clin Trials. 2017;52:10-9.

20. Stark LJ, Spear S, Boles R, Kuhl E, Ratcliff M, Scharf C, et al. A pilot randomized controlled trial of a clinic and home-based behaviora intervention to decrease obesity in preschoolers. Obesity (Silver Spring). 2011;19(1):134-41.

21. Gidding SS, Dennison BA, Birch LL, Daniels SR, Gillman MW, Lichtenstein AH, et al. Dietary recommendations for children and adolescents: a guide for practitioners: consensus statement from the American Heart Association. Circulation. 2005;112(13):2061-75.

22. National Cancer Institute Division of Cancer Control and Population Sciences. Comparing HEl-2015, HEl-2010 \& HEl-2005. [Internet]. 2018 Available from: https://epi.grants.cancer.gov/hei/comparing.html.
23. Boles RE, Scharf C, Filigno SS, Saelens BE, Stark L. Differences in home food and activity environments between obese and healthy weight families of preschool children. J Nutr Educ Behav. 2013;45(3):222-31.

24. Littell RC, Miliken GA, Stroup WW, Wolfinger RD, Schabenberger O. SAS for Mixed Models. 2nd Edition ed. Cary, NC: SAS institute, Inc.; 2006.

25. Reedy J, Krebs-Smith SM, Miller PE, Liese AD, Kahle LL, Park Y, et al. Higher diet quality is associated with decreased risk of all-cause, cardiovascular disease, and cancer mortality among older adults. J Nutr. 2014;144(6):881-9.

26. George SM, Ballard-Barbash R, Manson JE, Reedy J, Shikany JM, Subar AF, et al. Comparing indices of diet quality with chronic disease mortality risk in postmenopausal women in the Women's Health Initiative observational study: evidence to inform national dietary guidance. Am J Epidemiol. 2014;180(6):616-25.

27. Sotos-Prieto M, Bhupathiraju SN, Mattei J, Fung TT, Li Y, Pan A, et al. Changes in diet quality scores and risk of cardiovascular disease among US men and women. Circulation. 2015;132(23):2212-9.

28. Best JR, Goldschmidt AB, Mockus-Valenzuela DS, Stein Rl, Epstein LH, Wilfley $D E$. Shared weight and dietary changes in parent-child dyads following family-based obesity treatment. Health Psychol. 2016;35(1):92-5.

29. Looney S, Raynor H. Are changes in consumption of "healthy" foods related to changes in consumption of "unhealthy" foods during pediatric obesity treatment? Int J Environ Res Public Health. 2012;9:1368-78.

30. Anderson SE, Ramsden M, Kaye G. Diet qualities: healthy and unhealthy aspects of diet quality in preschool children. Am J Clin Nutr. 2016;103(6):1507-13

31. Golley RK, Magarey AM, Daniels LA. Children's food and activity patterns following a six-month child weight management program. Int J Pediatr Obes. 2011;6(5-6):409-14.

32. Wilfley DE, Saelens BE, Stein Rl, Best JR, Kolko RP, Schechtman KB, et al. Dose, content, and mediators of family-based treatment for childhood obesity: a multisite randomized clinical trial. JAMA Pediatr. 2017;171(12):1151-9.

33. Stark LJ, Clifford LM, Towner EK, Filigno SS, Zion C, Bolling C, et al. A pilot randomized controlled trial of a behavioral family-based intervention with and without home visits to decrease obesity in preschoolers. J Pediatr Psychol. 2014;39(9):1001-12.

\section{Ready to submit your research? Choose BMC and benefit from:}

- fast, convenient online submission

- thorough peer review by experienced researchers in your field

- rapid publication on acceptance

- support for research data, including large and complex data types

- gold Open Access which fosters wider collaboration and increased citations

- maximum visibility for your research: over $100 \mathrm{M}$ website views per year

At BMC, research is always in progress.

Learn more biomedcentral.com/submissions 